\title{
Metastatic Renal Cell Carcinoma Presenting as Gastrointestinal Bleeding
}

\author{
Christopher Hakim $^{a} \quad$ Avery Mendelson ${ }^{a} \quad$ Jalpa Patel ${ }^{b} \quad$ Julia Greer ${ }^{b}$ \\ Serge Sorser ${ }^{b}$ \\ aDepartment of Internal Medicine, Ascension Providence Hospital - Michigan \\ State University College of Human Medicine, Southfield, MI, USA; bepartment of \\ Gastroenterology, Ascension Providence Hospital - Michigan State University College of \\ Human Medicine, Southfield, MI, USA
}

\section{Keywords}

Renal cell carcinoma $\cdot$ Gastrointestinal bleed $\cdot$ Stomach $\cdot$ Metastasis

\begin{abstract}
Approximately $85 \%$ of kidney tumors are renal cell carcinoma (RCC). RCC commonly metastasizes to the lung, bone, and lymph nodes; however, gastric metastasis is exceedingly rare. We present an 86-year-old woman with left-sided RCC with known metastatic disease to the lungs, lymph nodes, and bone, who presented with acute blood loss anemia. After hemodynamic stabilization, esophagogastroduodenoscopy revealed a large infiltrative, polypoid, and ulcerated polyp in the gastric body. After complete polypectomy, histological examination demonstrated gastric mucosa ulcerated by clear-cell carcinoma, compatible with metastatic RCC. Our patient was successfully treated with palliative radiation to the gastric body.
\end{abstract}

\section{Introduction}

In 2019 , approximately 63,000 people in the USA were diagnosed with renal cell carcinoma (RCC) [1]. About one-third of patients with RCC present with metastatic disease to the lung (45\%), bone (30\%), and lymph nodes (22\%) [2-4]. Despite the propensity for RCC to metastasize, metastatic disease to the stomach is rare. Previous reports have described gastric disease presenting as epigastric pain, gastric ulcerations, and acute blood loss anemia [5-7]. We present a rare case of gastric metastasis from RCC causing upper gastrointestinal bleed. 


\section{Case Report}

An 86-year-old Caucasian woman presented to the emergency department due to melena for 2-weeks duration and 1 episode of hematemesis. Her past medical history was significant for right-sided breast cancer treated with mastectomy and radiation (1985) as well as left-sided RCC treated with nephrectomy (1991) with right side recurrence (2003) treated with partial nephrectomy. In 2009, the patient was found to have metastases to the lungs and mediastinal lymph nodes with eventual progression to the bone. During her disease course, she was treated with sunitinib and pazopanib, both tyrosine kinase inhibitors. On initial examination, her temperature was $36.8^{\circ} \mathrm{C}$ with vitals within normal limits. Her cardiopulmonary and abdominal examinations were unremarkable. Laboratory data demonstrated a white blood cell count $13.70 \mathrm{~K} / \mathrm{mcl}$, hemoglobin $6.7 \mathrm{gm} / \mathrm{dL}$ (baseline: 9.0-11.0 gm/dL), MCV $91.3 \mathrm{fL}$, platelet count $328 \mathrm{~K} / \mathrm{mcl}$, and BUN $57 \mathrm{mg} / \mathrm{dL}$, with an otherwise unremarkable comprehensive metabolic panel. Of note, she had known anemia of chronic disease; however, she presented acutely below her baseline. The patient was admitted under the hematology/oncology service for stabilization and further evaluation of gastrointestinal bleeding.

The gastroenterology service was consulted on day 1. The patient was started on continuous intravenous pantoprazole and transfused 2 units of packed RBCs. The patient was hemodynamically stable, and her hemoglobin level increased to $10.2 \mathrm{gm} / \mathrm{dL}$. She was scheduled for esophagogastroduodenoscopy (EGD) on hospitalization day 2.

Initial EGD shown in Figure 1 demonstrated a large, frond-like/villous, infiltrative, polypoid, and ulcerated noncircumferential polyp with no stigmata of recent bleeding in the gastric body. Biopsies were taken with cold forceps. Given suspicion for metastatic disease, radiation oncology was consulted, and radiation to the gastric body was initiated in order to control bleeding.

The patient was continued on IV pantoprazole and her hemoglobin stabilized. Given continued suspicion for malignancy, despite initial benign findings, a repeat EGD was scheduled for hospitalization day 7. During repeat EGD, a single 20-mm pedunculated polyp on the greater curvature of the gastric body was removed with a hot snare polypectomy. Histological examination shown in Figure 2 demonstrated gastric mucosa ulcerated by clear-cell carcinoma, compatible with metastatic clear-cell RCC. Radiation was resumed, and the patient completed 4 fractions prior to being discharged with scheduled outpatient follow-up.

Fig. 1. Large, frond-like/villous, infiltrative, polypoid, and ulcerated noncircumferential polyp in the gastric body.

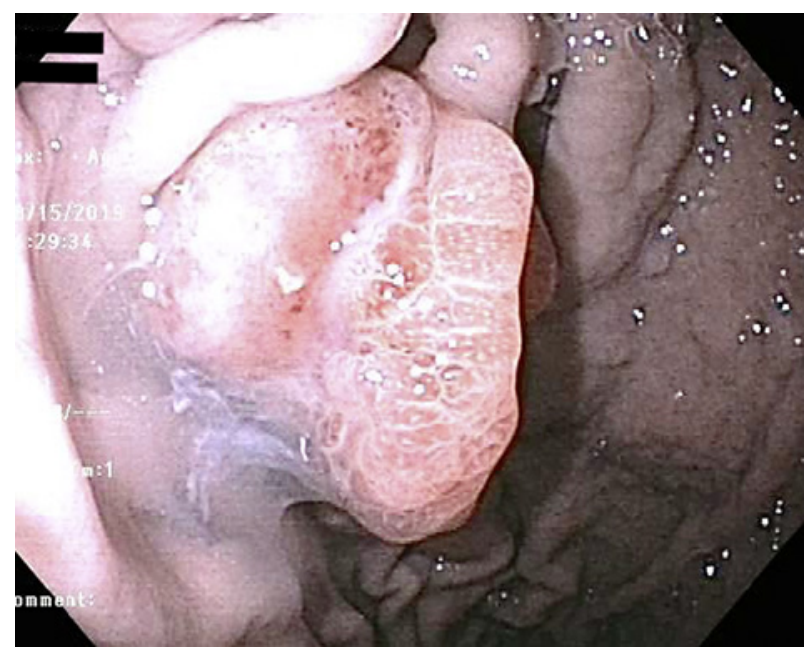


Fig. 2. Histologic examination demonstrating gastric mucosa (right) ulcerated by clear-cell carcinoma (left). Hematoxylin and eosin stain, $\times 100$ magnification.

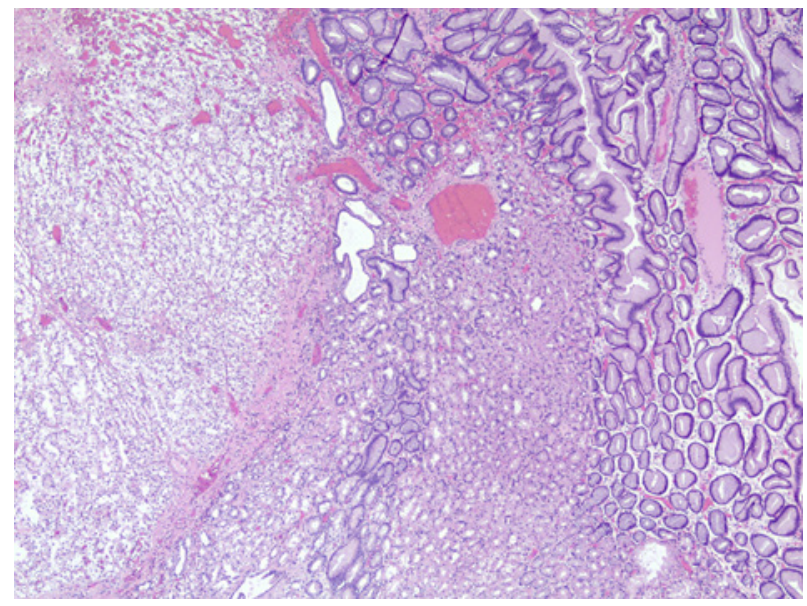

\section{Discussion}

In general, gastrointestinal metastasis is exceedingly rare, accounting for only $0.2-0.7 \%$ of gastric neoplasms [8, 9]. Metastatic disease has been commonly described in association with breast cancer $(27 \%)$, lung cancer $(23 \%)$, and melanoma (7\%). However, gastric metastasis from RCC is a rare phenomenon $[10,11]$. Signs and symptoms vary among patients; therefore, clinical suspicion for metastatic disease is imperative for proper diagnosis and treatment.

Clinical manifestations commonly associated with gastric metastases include blood loss anemia, gastrointestinal bleeding, abdominal pain, and dyspepsia [6, 7]. Similar to previously reported cases, our patient presented with acute blood loss anemia and gastrointestinal bleeding in the setting of known stage IV RCC. This led to suspicion for gastric metastasis.

Endoscopy is often necessary for diagnosis and localized treatment. In most reported cases, metastasis presented as a single, large polypoid lesion located in the gastric body [12]. Grossly, metastatic disease resembled a submucosal tumor with deep ulceration or central depression [13]. Histologically, metastatic disease is most commonly found in the submucosa with clear-cell histology as the predominant form [14].

Currently, there is no established treatment strategy for patients with renal cancer with metastatic disease. Initial management varies in relation to tumor resectability and prognostic risk factors. According to the 2020 National Comprehensive Cancer Network (NCCN) guidelines, systemic therapy is the preferred initial treatment option for patients with stage IV disease who have any poor risk features, clear-cell histology, and high-volume distant metastases $[4,15]$. Given our patient's extensive disease and previously failed treatments, we elected for palliative radiation to control gastrointestinal bleeding.

Gastric metastasis in RCC usually occurs later in the disease course. Concomitant metastases to other organs are often reported, and therefore, findings of gastric disease may serve as a marker of RCC progression and severity. In general, the outcome with metastatic RCC is poor with 5 -year survival rates of $12 \%$ [4]. Given the high mortality rate, clinical suspicion for metastatic disease is imperative in patients with atypical presentations. As evidenced in our case, a presentation of acute blood loss anemia and melena leads to the diagnosis of gastric metastasis.

\section{Statement of Ethics}

Subject(s) have given their written informed consent to publish their case (including publication of images). 


\section{Conflict of Interest Statement}

The authors have no conflicts of interest to declare.

\section{Funding Sources}

The authors have no funding sources to disclaim.

\section{Author Contributions}

Christopher Hakim, Avery Mendelson, and Jalpa Patel analyzed and interpreted the patient data regarding gastrointestinal bleed and renal cell carcinoma. Serge Sorser and Julia Greer performed the endoscopic evaluation of the patient and histological examination of the polyp. Christopher Hakim, Avery Mendelson, Jalpa Patel, Serge Sorser, and Julia Greer were all major contributors in writing the manuscript. All authors read and approved the final manuscript.

\section{References}

1 Siegel RL, Miller KD, Jemal A. Cancer treatment and survivorship statistics, 2019. CA Cancer J Clin. 2019;69(1): 363-85.

2 Bianchi M, Sun M, Jeldres C, Shariat SF, Trinh QD, Briganti A, et al. Distribution of metastatic sites in renal cell carcinoma: a population-based analysis. Ann Oncol. 2012;23(4):973-80.

3 Gong J, Maia MC, Dizman N, Govindarajan A, Pal SK. Metastasis in renal cell carcinoma: biology and implications for therapy. Asian J Urol. 2016;3(4):286-92.

4 Motzer RJ, Jonasch E, Michaelson MD, Nandagopal L, Gore JL, George S, et al. NCCN guidelines insights: kidney cancer, version 2.2020. J Natl Compr Canc Netw. 2019;17(11):1278-85.

5 Kim MY, Jung HY, Choi KD, Song HJ, Lee JH, Kim DH, et al. Solitary synchronous metastatic gastric cancer arising from $t 1 b$ renal cell carcinoma: a case report and systematic review. Gut Liver. 2012;6(3):388-94.

6 Al Juboori A, Kaur S, Reddy A. Metastatic renal cell carcinoma presenting as gastric ulcer: case report and literature review. Case Rep Gastrointest Med. 2017;2017:2509294.

7 Sakurai K, Muguruma K, Yamazoe S, Kimura K, Toyokawa T, Amano R, et al. Gastric metastasis from renal cell carcinoma with gastrointestinal bleeding: a case report and review of the literature. Int Surg. 2014;99(1): 86-90.

8 De Palma GD, Masone S, Rega M, Simeoli I, Donisi M, Addeo P, et al. Metastatic tumors to the stomach: clinical and endoscopic features. World J Gastroenterol. 2006;12(45):7326-8.

9 Kobayashi O, Murakami H, Yoshida T, Cho H, Yoshikawa T, Tsuburaya A, et al. Clinical diagnosis of metastatic gastric tumors: clinicopathologic findings and prognosis of nine patients in a single cancer center. World J Surg. 2004;28(6):548-51.

10 Namikawa T, Hanazaki K. Clinicopathological features and treatment outcomes of metastatic tumors in the stomach. Surg Today. 2014;44(8):1392-9.

11 Weigt J, Malfertheiner P. Metastatic disease in the stomach. Gastrointest Tumors. 2015;2(2):61-4.

12 Rita H, Isabel A, Iolanda C, Alexander H, Pedro C, Liliana C, et al. Treatment of gastric metastases from renal cell carcinoma with endoscopic therapy. Clin J Gastroenterol. 2014;7(2):148-54.

13 Oda I, Kondo H, Yamao T, Saito D, Ono H, Gotoda T, et al. Metastatic tumors to the stomach: analysis of 54 patients diagnosed at endoscopy and 347 autopsy cases. Endoscopy. 2001;33(6):507-10.

14 Pollheimer MJ, Hinterleitner TA, Pollheimer VS, Schlemmer A, Langner C. Renal cell carcinoma metastatic to the stomach: single-centre experience and literature review. BJU Int. 2008;102(3):315-9.

15 Mejean A, Ravaud A, Thezenas S, Colas S, Beauval JB, Bensalah K, et al. Sunitinib alone or after nephrectomy in metastatic renal-cell carcinoma. N Engl J Med. 2018;379(5):417-27. 